\title{
ULTRASONOGRAPHIC EVALUATION OF HEPATIC METASTASES OF MALIGNANT DISEASES WITH CYTOPATHOLOGICAL CORRELATION
}

\author{
SULTANA $F^{1}$, AL-AZAD $\mathrm{S}^{2}$, SATTAR A ${ }^{3}$, HOSSAIN MZ ${ }^{4}$, DEEPA ZS ${ }^{5}$, CHATTERJEE $\mathrm{S}^{6}$
}

\begin{abstract}
:
Objective: A prospective study was carried out to evaluate the role of ultrasonography in the diagnosis of hepatic metastasis and also to preoperative determination of hepatic metastasis and its validity in diagnostic process.

Methods: A total of 52 patients having hepatic metastasis were enrolled in this study taken from Department of Hepatology of two tertiary level medical institutions. After sonographic evaluation of the metastatic lesion, cytopathology was done in all these patients. With written informed consent they were taken care of from the admission up to diagnosis of the hepatic metastasis, and subsequent management in hepatology unit.

Place and period of study: Department of Radiology \& Imaging, Department of Pathology and Department of Hepatology of Bangabandhu Sheikh Mujib Medical University (BSMMU) Hospital and of Dhaka Medical College Hospital (DMCH), during the period between July 2006 and June 2007.

Results: The mean age of the patients was 51.20 11.9 years, ranging from 21 to 69 years. The highest incidence was in 60-69 years age group. The male and female ratio was 3.7:1. The most common symptom was pain with upper abdominal mass (73.1\%), and others were anorexia and nausea with weight loss (67.3\%), jaundice (28.8\%) and ascites (23.1\%). Only the right lobe of the liver was involved in $51.9 \%$ cases, left lobe in $28.8 \%$ and in $19.2 \%$ both lobes of the liver were affected. Hepatic metastasis was found as unifocal lesion in $7.7 \%$ and multifocal lesions in $92.3 \%$ cases. The echopattern was found $57.7 \%$ hyperechoic, $28.8 \%$ hypoechoic, and rest $13.5 \%$ mixed pattern. All cases were metastasis in sonography findings whereas $90.4 \%$ cases were metastasis and $9.6 \%$ other lesions in cytopathological findings. The validity of ultrasonography were determined by calculating sensitivity, specificity, accuracy, positive predictive value and negative predictive value which were 93.6\%, 80.0\%, 92.3\%, 97.8\% and $57.1 \%$ respectively.
\end{abstract}

Key words: Hepatic metastasis, hepatic mass, ultrasonography, cytopathology, validity.

J Dhaka Med Coll. 2014; 23(2) : 239-244.

\section{Introduction}

Hepatic metastases are common in the adult and 20 times more frequent than primary malignancy of liver ${ }^{1}$. The liver is second in prevalence only to regional lymph node as a site of metastatic disease. Approximately 25\% to $50 \%$ of all patients who die of malignant disease have metastatic disease to the liver at autopsy ${ }^{1}$. A silent primary neoplasm with hepatic metastases is most often found to be a result of pancreatic, stomach or lung carcinoma ${ }^{2}$. Metastases are nearly always multiple. They are more frequently encountered in the right lobe than the left as large mass of the right lobe and its greater blood flow $^{3}$. The primary neoplasm is asymptomatic

1. Dr. Farhana Sultana, Radiologist, Department of Radiology \& Imaging, Sylhet MAG Osmani Medical College Hospital, Sylhet.

2. Prof. Salahuddin Al-Azad, Professor, Department of Radiology \& Imaging, Bangabandhu Sheikh Mujib Medical University (BSMMU), Dhaka.

3. Dr. Asifa Sattar, Assistant Professor, Department of Radiology \& Imaging, Sir Salimullah Medical College \& Mitford Hospital, Dhaka.

4. Dr. Mohammed Zaid Hossain, Associate Professor, Department of Medicine, Dhaka Medical College, Dhaka

5. Dr. Zereen Sultana Deepa, Medical Officer, Department of Radiology \& Imaging, Bangabandhu Sheikh Mujib Medical University (BSMMU), Dhaka.

6. Dr. Sutapa Chatterjee, Radiologist, Sadar Hospital, Satkhira.

Correspondence : Dr. Farhana Sultana, Radiologist, Department of Radiology \& Imaging, Sylhet MAG Osmani Medical College Hospital, Sylhet. 
in about half the patients ${ }^{4}$. However massive destruction of liver substance or direct obstruction to major bile ducts may occur ${ }^{5}$. There is usually rapid liver enlargement with fever, weight loss and jaundice. Peritoneal dissemination frequently results in ascites ${ }^{4}$. Significant advances in cross-sectional imaging modalities like ultrasound now allow not only detection but often non- invasive characterization of focal and diffuse hepatic process. The presence of metastatic disease to the liver is a prima determinate of survival. Over the last decade, there have been tremendous advances in the treatment of metastatic disease of the liver. Liver resection or liver directed therapy is justified to select patients when extrahepatic malignancy is not present and the patients can tolerate therapy ${ }^{3}$.

In patients with suspected metastatic disease, several imaging procedures are used to detect liver metastases. They include ultrasonography (USG), computed tomography (CT), magnetic resonance imaging (MRI), angiography and radio nuclide scanning. In general, however, USG, CT, and MRI are more accurate than angiography or radionuclide scanning. CT is more specific for detection of tumour nodules but because of its less availability, expense and radiation hazards, it is reserved for complicated cases which can not be detected by other modalities. MRI is also specific but more expensive and lack of its availability makes it more difficult to use as primary modality of investigation. Ultrasound is an excellent screening modality for metastatic liver disease because of its relative accuracy, speed, lack of ionizing radiation and availability $^{6}$. It allows not only detection but often non-invasive characterization of focal and diffuse hepatic process. It is also selected as because it can be done repeatedly and rapidly with least expense. When a patient with previously diagnosed malignancy subsequently develops a liver mass, a fine needle aspiration is performed for histopathological confirmation $^{7}$. Ultrasonographic guidance is usually preferred for its simplicity, capability of real time monitoring and flexible needle tract placement ${ }^{6,7}$. Cytopathological confirmation is also needed for diagnosis of hepatic metastasis ${ }^{5}$. Therefore, the aims of the present study were to correlate ultrasonography and cytopathological findings in hepatic metastases and to determine the sensitivity and specificity of ultrasonography to diagnose hepatic metastases of malignant diseases compared with cytopathological findings.

\section{Methods}

This was a prospective, cross-sectional and consecutive observational study which was done in the Department of Radiology \& Imaging and Department of Pathology and Department of Hepatology of Bangabandhu Sheikh Mujib Medical University (BSMMU) Hospital and Dhaka Medical College Hospital (DMCH), between July 2006 and June 2007. A total of 52 patients were included in this study after taking written informed consent from them, who could fulfill the selection criteria as defined below from Department of Hepatology of BSMMU Hospital and $\mathrm{DMCH}$.

\section{Inclusion Criteria:}

i) Patients with age of 21 to 69 years,

ii) Patients having clinical manifestations of hepatic metastases of malignant diseases, and

iii) Patients having a known primary malignancy with sonographic evidence and cytopathological reports.

\section{Exclusion criteria:}

i) Patients unwilling to give consent.

ii) Patients who has not undergone pathological examination, and

iii) Patients with abnormal bleeding profile.

At first all these patients were evaluated by detail history, clinical examination with special emphasis on hepato-biliary sytem. Sonographic examinations were then performed for the evaluation of hepatic metastases. Lobe distribution, multiplicity, echocharacter were evaluated in all the cases. Then fine needle aspiration under ultrasonographic guidance and cytopathological examinations were done and finally were correlated with the sonographic diagnoses.

Data were collected in a predesigned structured data collection sheet. All the relevant collected 
data were compiled and statistical analysis were done by using SPSS version 11.0. The results were presented in tables. $Z$ test, Chisquare test and validity test were done where applicable.

\section{Results}

This study included 52 patients having metastasis in liver diagnosed clinically. They were divided into five age groups. The mean age of the patients was $51.20 \pm 11.9$ years, ranging from 21 to 69 years. The maximum patients were in $>60$ years age group and least was in 21 to 29 years age group (Table-I). Here, $41(78.8 \%)$ were male and $11(21.2 \%)$ were female (Table-II). The common symptoms in patients, e.g. $38(73.1 \%)$ had pain with upper abdominal mass followed by $35(67.3 \%)$ anorexia and nausea with weight loss, $15(28.8 \%)$ jaundice and $12(23.1 \%)$ ascites (Table-III).

Table-I

Age distribution of study subjects $(n=52)$

\begin{tabular}{lccc}
\hline $\begin{array}{l}\text { Age group } \\
\text { (years) }\end{array}$ & Number & Percentage & $\begin{array}{c}\text { Mean } \pm \text { SD } \\
\text { (years) }\end{array}$ \\
\hline $21-29$ & 3 & 5.8 & $51.20 \pm 11.9$ \\
$30-39$ & 7 & 13.5 & \\
$40-49$ & 11 & 21.2 & \\
$50-59$ & 14 & 26.9 & \\
$60-69$ & 17 & 32.7 & \\
\hline
\end{tabular}

Table-II

Sex distribution of patients $(n=52)$

\begin{tabular}{lcc}
\hline Sex group & Number & Percentage \\
\hline Male & 41 & 78.8 \\
Female & 11 & 21.2 \\
\hline
\end{tabular}

$* * * Z=4.15, P<0.001$

Table-III

Presenting features of the patients $(n=52)$

\begin{tabular}{lcc}
\hline Features & $\begin{array}{c}\text { Number } \\
\text { of patients }\end{array}$ & Percentage \\
\hline $\begin{array}{l}\text { Pain with upper } \\
\text { abdomen mass }\end{array}$ & 38 & 73.1 \\
$\begin{array}{l}\text { Anorexia and nausea } \\
\text { with weight loss }\end{array}$ & 35 & 67.3 \\
Jaundice & 15 & 28.8 \\
Ascites & 12 & 23.1 \\
\hline
\end{tabular}

Mainly right lobe of the liver was involved in most cases i.e. 27 (51.9\%) patients, and among the others left lobe of the liver involved in $15(28.8 \%)$ patients and the rest $10(19.2 \%)$ were involved in both lobes of the liver (Table-IV). Among 52 patients, 4(7.7\%) were with unifocal lesions and 48(92.3\%) multifocal lesions (TableV). In patients diagnosed by ultrasonography, it was observed that $15(28.8 \%)$ were hypoechoic, 30(57.7\%) hyperechoic and rest $7(13.5 \%)$ mixed pattern (Table-VI). Of total 52 cases, $45(86.5 \%)$ cases were metastasis and $7(14.5 \%)$ cases were other lesions in sonography findings. On the other hand $47(90.4 \%)$ cases were metastasis and $5(9.6 \%)$ cases were other lesions in cytopathological findings (Table-VII). Every patient having metastasis which was diagnosed by sonography was correlated with cytopathological diagnosis after collection of the report from the respective case. Of total 52 cases, $45(86.5 \%)$ cases were hepatic metastasis and $7(14.5 \%)$ cases were other lesions in sonography findings. Only 1 case was found as other lesions in cytopathological among the all hepatic metastasis, which were diagnosed by ultrasonogram. On the other hand, 47(90.4\%) cases were hepatic metastasis and 5(9.6\%) cases were other lesions in cytopathological findings. Among 7 other lesions cases which were diagnosed by ultrasonogram, 3 cases were hepatic metastasis and the rest 4 cases were other lesions in cytopathological findings (Table-VIII).

Table-IV

Distribution of lesions in different lobes $(n=52)$

\begin{tabular}{lcc}
\hline Lobe & Number of Cases & Percentage \\
\hline Right lobe & 27 & 51.9 \\
Left lobe & 15 & 28.8 \\
Both lobes & 10 & 19.2 \\
\hline
\end{tabular}

Table-V

Metastasis based on unifocal and multifocal lesions by sonographic diagnosis $(n=52)$

\begin{tabular}{lcc}
\hline Lesions & \multicolumn{2}{c}{ Metastasis } \\
& Number of cases & Percentage \\
\hline Unifocal & 4 & 7.7 \\
Multi focal & 48 & 92.3 \\
\hline
\end{tabular}


Table-VI

Echopattern of lesions ( $n=52)$

\begin{tabular}{lcc}
\hline Echogenicity & Number of cases & Percentage \\
\hline Hypoechoic & 15 & 28.8 \\
Hyperechoic & 30 & 57.7 \\
Mixed & 7 & 13.5 \\
\hline
\end{tabular}

Table-VII

Analysis of metastasis and other lesions $(n=52)$

\begin{tabular}{lcc}
\hline Modality & Metastasis & Other lesions \\
\hline Ultrasonography & $45(86.5 \%)$ & $07(14.5 \%)$ \\
Cytopathology & $47(90.4 \%)$ & $05(9.6 \%)$ \\
\hline
\end{tabular}

Table-VIII

Sonography and cytopathological correlation of metastasis

\begin{tabular}{|c|c|c|c|}
\hline \multirow[t]{2}{*}{ Sonography } & \multicolumn{3}{|c|}{ Cytopathological diagnosis } \\
\hline & $\begin{array}{l}\text { positive for } \\
\text { metastasis }\end{array}$ & $\begin{array}{l}\text { negative for } \\
\text { metastasis }\end{array}$ & Total \\
\hline $\begin{array}{l}\text { positive for } \\
\text { metastasis }\end{array}$ & 44 & 1 & 45 \\
\hline $\begin{array}{l}\text { negative for } \\
\text { metastasis }\end{array}$ & 3 & 4 & 7 \\
\hline Total & 47 & 5 & 52 \\
\hline
\end{tabular}

$\left(\chi^{2}=21.02, p=0.001, d f=1\right)$

The validity of ultrasonography were determined by calculating sensitivity, specificity, accuracy, positive predictive value and negative predictive value which were $93.6 \%, 80.0 \%, 92.3 \%, 97.8 \%$ and $57.1 \%$ respectively (Table-IX).

Table-IX

Validity test of the ultrasound in diagnosis of metastasis

\begin{tabular}{lc}
\hline Validity test & Percentage \\
\hline Sensitivity & 93.6 \\
Specificity & 80.0 \\
Accuracy & 92.3 \\
Positive predictive value & 97.8 \\
Negative predictive value & 57.1 \\
\hline
\end{tabular}

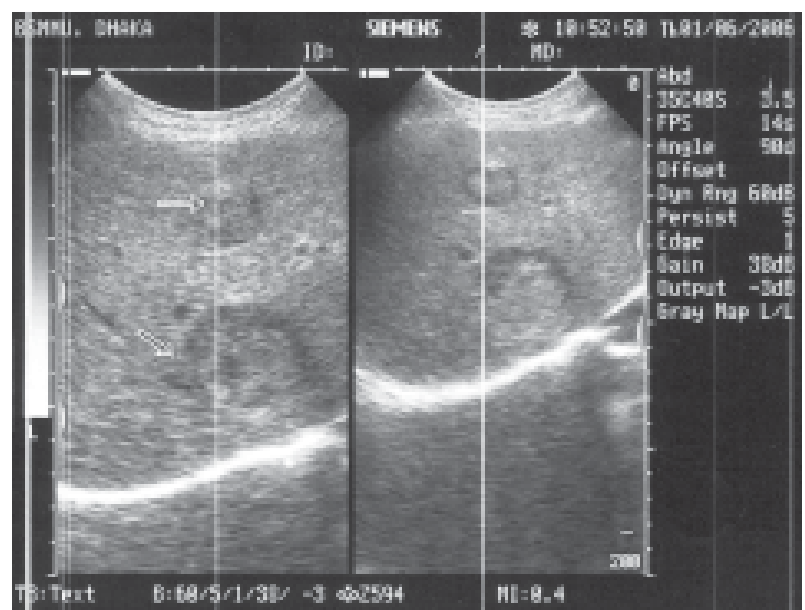

Fig.-1. Sonographic image of multiple metastatic lesions of the liver (Bull's eye appearance) of a 58 years old female patient.

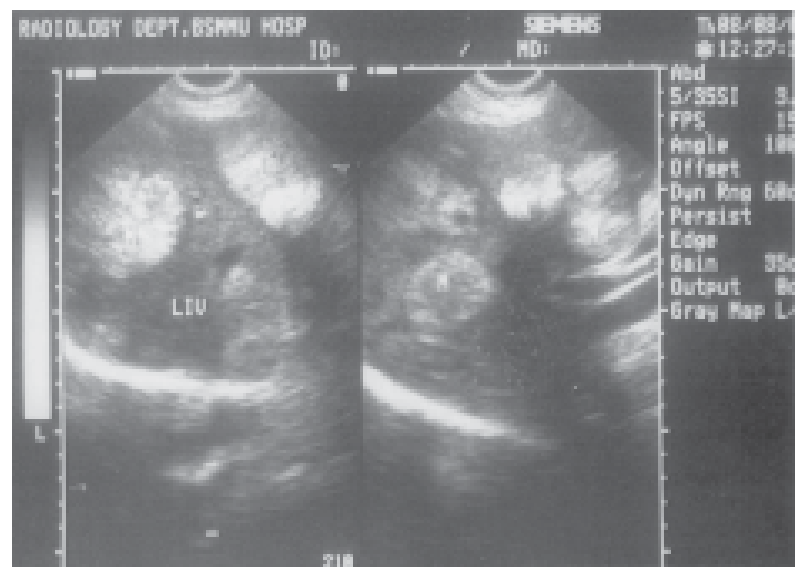

Fig.-2. Sonographic image showing multiple hyperechoic metastatic lesions of the right lobe of the liver of a 40 years old male patient.

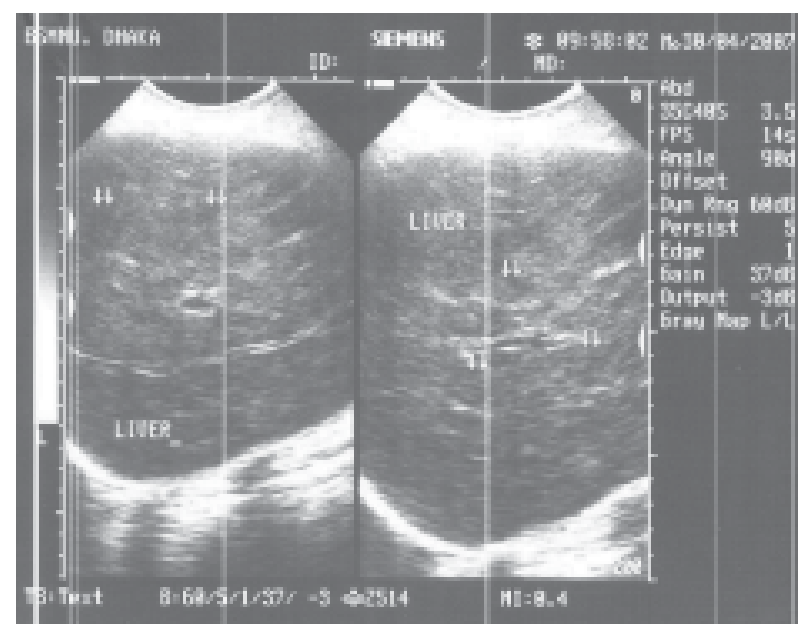

Fig.-3. Sonographic image showing multiple mixed echogenic metastatic lesions of the right lobe of liver of a 55 years old male patient. 


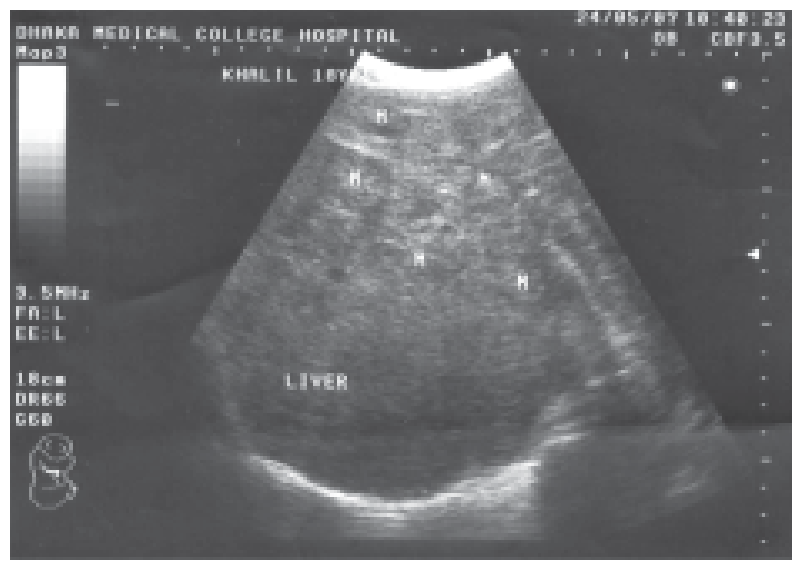

Fig.-4. Sonographic image of multiple hypoechoic metastatic lesions of the liver of a 63 years old male patient.

\section{Discussion}

Turkay et al. ${ }^{8}$ have shown in their series that the mean age of the patients was $59.7 \pm 11.99$ years which is slightly higher than that of the present study. Charnsangavej et al. ${ }^{9}$ observed that the male female ratio was 3:1 to $4: 1$ which is in agreement with the present study. Yoshida et al. ${ }^{10}$ have shown $85.0 \%$ cases of metastases were multiple which is similar with the present study where $92.3 \%$ patients were multifocal lesions. This is also similar to the present study. Seheible et al. ${ }^{11}$ have shown in a prospective study on 76 patients of hepatic metastasis that echographic pattern was found $18.0 \%$ hypoechoic, $37.0 \%$ hyperechoic, $28.0 \%$ was mixed pattern and $17.0 \%$ Bull's eye lesions. The results of the present study are not similar to the above mentioned study as they also observed the bull's eye lesions.

Turkay et al. ${ }^{8}$ observed the sensitivity of ultrasonography in diagnosis of hepatic metastasis which was $85-90 \%$. Almost similar value was obtained by Reinhold et al. ${ }^{12}$. Both investigations support the results of the present study. Dick and Watkinson ${ }^{1}$ found the specificity of ultrasonography in diagnosis of hepatic metastasis was $80 \%$. This finding is similar with the present study where specificity was found $80.0 \%$. Turkay et al. ${ }^{8}$ further correlated the ultrasonographic findings with post-operative cytopathology specimen. They have observed that the positive predictive value was $97.8 \%$ with the histopathology findings. The results of the ultrasonography and cytopathological findings observed in the present study also support the above evidence. Turkay et al. ${ }^{8}$ found accuracy $73 \%$ to $94 \%$. Middleton et al. ${ }^{13}$ and Fisher et al. ${ }^{14}$ also found accuracy of ultrasonography, which were $93.0 \%$ and $86.0 \%$ respectively. The present study strongly supports the above mentioned studies.

It was also observed that the negative predictive value in the present study was $57.1 \%$. However, there is no known evidence of such study on this regard till date in our country. The results of both ultrasonography and cytopathology in the present series are almost similar. Therefore, the inference can be drawn that ultrasonography is a good modality in the evaluation of hepatic metastasis.

\section{Conclusion}

As the cytopathological diagnosis of the present study significantly correlated with the ultrasonographic findings and the validity tests are almost identical as observed by other investigators, it can be concluded that the ultrasonography is a useful diagnostic modality in diagnosis of hepatic metastasis. Hence, ultrasonography has definite value in the diagnosis of hepatic metastasis. Moreover, it is simple, non-invasive, rapid diagnostic tool without having any risk of radiation.

\section{References}

1. Dick R, Watkinson A. The liver and spleen. In: Sutton D. ed. Textbook of radiology and imaging. $7^{\text {th }}$ ed. London: Elsevier Churchill Livingstone, 2003: p.737-8, 772-3.

2. Jeffrey D. McTavish, Ros PR. Hepatic mass lesions. In: Haaga JR, Lanjieri CF, Gilkeson RC, eds. CT and MR of whole body. Vol. 2. $4^{\text {th }}$ ed. St. Louis: Mosby; 2003: p.1296-7.

3. Paulson EK. Evaluation of the liver for metastatic disease. Semin Liver Dis 2001; 21(2): 225-36.

4. Finlayson NDC, Hayes PC, Simpson RJ. Diseases of the liver \& biliary system. In: Haslett C, Chilvers ER, Hunter JAA, Boon NA, eds. Davidson's principles and practice of medicine. ed $18^{\text {th }}$ ed. Edinburgh: Churchill Livingstone; 1999: p.724-5.

5. Crawford JM. Liver and baliary tract. In: Kumar V, Abbas AK, Fausto N, eds. Robbins and Cotran pathologic basis of disease. $7^{\text {th }}$ ed. Philadelphia: W.B. Saunders; 2004: p.927. 
6. Withers CE, Wilson SR. The liver. In: Rumack CM, Wilson SR, Charboneau JW, eds. Diagnostic ultrasound. $2^{\text {nd }}$ ed. St Louis: Mosby; 1998: p.134-5.

7. Tsui WM, Cheng F, Lee Y. Fine needle Aspiration cytology of liver tumors. Ann Contemp Diagn Pathol 1998; 2: 79-93.

8. Türkay C, Elagöz S, Yönem O, Yüksel I, Murat I. The diagnostic value of ultrasonography-guided fine needle aspiration biopsy from liver and pancreas. Turk J Gastroenterol 2002; 13(1): 53-5.

9. Charnsangavej C, Loyer EM, Lyer RV,Choi H, Kaur $\mathrm{H}$. Tumours of the liver, bile duct, and pancreas. In: Current problems in diagnostic radiology. 2000: p.29-88.

10. Yoshida T, Matsue H, Okazaki N, Yoshino M. Ultrasonographic differentiation of hepatocellular carcinoma from metastatic liver cancer. J Clin Ultrasound 1987; 15(7): 431-7.

11. Scheible W, Gosink BB, Leopold GR. Gray scale echographic pattern of hepatic metastatic disease. AJR 1977; 129(6): 983-7.

12. Reinhold C, Hammers L, Taylor CR, QuedensCase CL, Holland CK, Taylor KJW. Characterization of focal hepatic lesions with duplex sonography: findings in 198 patients. AJR 1995; 164(5): 1131-5.

13. Middleton WD, Hiskes SK, Teefay SA, Boucher LD. Small (1.5 cm or less) liver metastases: USguided biopsy. Radiology 1997; 205(3): 729-32.

14. Fisher AJ, Paulson EK, Sheafor DH, Simmons CM, Nelson RC. Small lymph nodes of the abdomen, pelvis, and retroperitoneum: usefulness of sonographically guided biopsy. Radiology 1997; 205(1): 185-90. 